\title{
Performance of phenol-acclimated activated sludge in the presence of various phenolic compounds
}

\author{
Jun-Wei Lim $\cdot$ Je-Zhen Tan $\cdot$ Chye-Eng Seng
}

Received: 18 October 2012/ Accepted: 25 March 2013/Published online: 9 April 2013

(c) The Author(s) 2013. This article is published with open access at Springerlink.com

\begin{abstract}
The objective of this study was to evaluate the performance of phenol-acclimated activated sludge in the presence of various phenolic compounds in the separated batch reactors. The phenol-acclimated activated sludge was observed to be capable of completely removing phenol, $o$-cresol, $m$-cresol, and 4-chlorophenol. Nevertheless, in the presence of 2-chlorophenol and 3-chlorophenol merely at $50 \mathrm{mg} / \mathrm{L}$, incomplete removal of these phenolic compounds were noticed. The specific oxygen uptake rate patterns obtained for phenol, $o$-cresol, $m$-cresol, and 4-chlorophenol could be used to approximate the end point of these phenolic compounds removal as well as to monitor the growth of biomass. As the 2-chlorophenol and 3 -chlorophenol were only partially removed in the mixed liquor, the patterns of specific oxygen uptake rate attained for these phenolic compounds were not feasible for the similar estimation. The calculated toxicity percentages show the toxicity effects of phenolic compounds on the phenol-acclimated activated sludge followed the order of 2-chlorophenol $\approx 3$-chlorophenol > 4-chlorophenol > $o$-cresol $\approx m$-cresol $>$ phenol.
\end{abstract}

Keywords: Phenol-acclimated activated sludge . Phenolic compound removal · Biomass growth · Specific oxygen uptake rate $\cdot$ Toxicity percentage

J.-W. Lim $(\varangle) \cdot$ J.-Z. Tan · C.-E. Seng

School of Chemical Sciences, Universiti Sains Malaysia, 11800 Penang, Malaysia

e-mail: jun_wei_85@yahoo.com

J.-Z. Tan

e-mail: tanjezhen@yahoo.com

C.-E. Seng

e-mail: ceseng@usm.my

\section{Introduction}

Phenolic compounds such as phenol, chlorophenols, and cresols are found in the mixture with diverse concentrations in the aqueous effluents discharged from a huge range of industrial processes, e.g., during the production of fungicides and herbicides, oil and petroleum refining processes, solvents, paints, and wood preservative industries (Kim and Moon 2005; Lee et al. 2005; Michalowicz and Duda 2007). Owing to their high toxicity effects and suspected carcinogenicity and mutagenesis to living organisms, the release of phenolic compounds into the receiving waters would cause serious environmental problems. Therefore, the removal of phenolic compounds from the wastewaters is of great importance.

Physical and chemical methods such as solvent extraction, ion exchange, adsorption, and chemical oxidation are usually used to treat wastewaters containing phenolic compounds. However, these processes often lead to the production of toxic intermediates and the costs involved are expensive. Biological treatment process of phenolic compounds has been proven to be more cost effective, practical, and highly reliable as it leads to low possibility of by-product formation. Different kinds of batch and continuous processes which apply biological approach are extensively employed to treat wastewaters containing phenolic compounds (Moharikar and Purohit 2003; Nuhoglu and Yalcin 2005; Zhao et al. 2009; Saravanan et al. 2011). Nevertheless, most of the studies only concentrated on the use of activated sludge to remove the target compound in which the activated sludge had been acclimated early. Thus, the presence of the mixture of phenolic compounds in the industrial wastewaters warrant further assessment on the capability of single phenolic compound acclimated activated sludge to treat these wastewaters. 
Biomass growth is defined as the increase of the quantity of cellular constituents and structures which is accompanied by the increase in size or number of individual cells or both (Cervantes et al. 2006). When the biomass grows in a culture medium, it will undergo several phases of growth, namely lag phase of growth, exponential phase of growth, stationary phase of growth, and death phase of growth. Lag phase of growth is defined as no significant biomass growth albeit excess of growth substrate is available. This is because the biomass starts to acclimate in the new environment particularly in the presence of unfamiliar new growth substrate. Following the lag phase of growth, exponential phase of growth will prevail. During this phase, the quantity of biomass will increase exponentially with time and last until the growth substrate is exhausted in the culture medium. The growth rate of biomass is usually being assessed during this phase. When the stationary phase of growth is approaching, the rate of biomass growth will slow down until the point at which the growth rate is equal to the death rate of biomasses. Finally, the death phase of growth shows a decline of biomass quantity with time due to the death or because biomass cell lysis rate is higher than the growth rate. The presence of various phenolic compounds in the wastewaters would definitely affect the growth of single phenolic compound acclimated activated sludge. The growth of this biomass would be adversely inhibited especially in the presence of more toxic phenolic compounds such as chlorophenols in the wastewaters. Thus, the degree of inhibition of various phenolic compounds must be further investigated to comprehend the growth trends of single phenolic compound acclimated activated sludge in the bioreactor during the commencement of treatment process.

Specific oxygen uptake rate (SOUR) measures the rate of dissolved oxygen (DO) consumption by definite quantity of activated sludge which represents the activity of activated sludge notably in the presence of organic substrate (Yoong et al. 2000; Archibald et al. 2001). In addition, the oxygen uptake rate (OUR) by the activated sludge was also regarded as an important tool for toxicity assessment (Arslan-Alaton and Akmehmet Balcioglu 2002) in which high toxicity was characterized by low OUR and vice versa. Leong et al. (2011) had shown that the bioactivity of activated sludge dropped approximately $30 \%$ when the phenol concentration was increased to $400 \mathrm{mg} / \mathrm{L}$ and further declined to more than $60 \%$ when the activated sludge was exposed to phenol concentration of $2,000 \mathrm{mg} / \mathrm{L}$. Moreover, the pattern of SOUR profile study during the biodegradation of a particular organic substrate by the activated sludge can also be used as a reference to reveal the profile pattern of that organic substrate degradation (Young 1999). Nevertheless, the studies on SOUR profiles for the degradation of phenolic compounds using single phenolic compound acclimated activated sludge are still lacking and it is important that studies in in this area are done.

The aim of this study was to investigate the effects of various phenolic compounds, namely phenol, $o$-cresol, $m$-cresol, 2-chlorophenol (2-CP), 3-chlorophenol (3-CP), and 4-chlorophenol (4-CP) on phenol-acclimated activated sludge in terms of the respective phenolic compounds removal efficiency and biomass growth. The activities of phenol-acclimated activated sludge measured as SOUR were also assessed to attest the feasibility of relating them to the profile patterns of phenolic compounds removal and biomass growth.

\section{Materials and methods}

\section{Source of activated sludge}

Activated sludge was originally obtained from a municipal sewage treatment plant and acclimated in the sequencing batch reactor (SBR) with the feed solutions (culture medium) containing $(\mathrm{mg} / \mathrm{L})$ : peptone (32), sucrose (109),

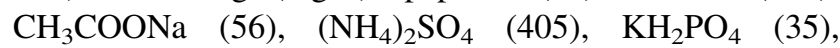
$\mathrm{K}_{2} \mathrm{HPO}_{4}(180), \mathrm{MgSO}_{4}(49), \mathrm{NaHCO}_{3}(354), \mathrm{FeCl}_{3} 6 \mathrm{H}_{2} \mathrm{O}$ (10) and $\mathrm{CaCl}_{2}$ (42). The SBR was operated with five operational periods which were FILL, REACT, SETTLE, DRAW, and IDLE in the ratio of 0:12:1.5:1:9.5 for a cycle time of $24 \mathrm{~h}$. During each cycle, $9 \mathrm{~L}$ of feed solution was added into the reactor and equal volume of treated effluent was withdrawn from the reactor during the DRAW period. As the total working volume of the SBR was $12.8 \mathrm{~L}$, a mixed liquor volume of $320 \mathrm{~mL}$ was wasted from the reactor at the end of the REACT period to maintain the sludge age of 40 days. Following the acclimation to the feed solution, the SBR was spiked with increasing concentration of phenol up to the concentration of $200 \mathrm{mg} / \mathrm{L}$ in the feed solution. Once the quasi-steady state (defined as a fairly constant react time for the complete mineralization of phenol in the SBR) was reached, which took nearly 5 months time, the mixed liquor volatile suspended solids (MLVSS) concentration and sludge volume index (SVI) value were measured and found to fall within the range of $5000 \pm 100 \mathrm{mg} / \mathrm{L}$ and $80 \pm 7 \mathrm{~mL} / \mathrm{g}$, respectively. The wasted mixed liquor for the maintenance of sludge age during this stage was used for the batch experiment studies with the procedure being outlined in the following section.

\section{Setting up of batch experiment}

The batch experiment was carried out in the beaker with a total working volume of $2000 \mathrm{~mL}$. The batch reactor 
Table 1 Concentrations of phenolic compounds in the feed solution

\begin{tabular}{llrlrl}
\hline Phenolic compound & Concentrations $(\mathrm{mg} / \mathrm{L})$ & & \\
\hline Phenol & 50 & 100 & 200 & 300 & 400 \\
-cresol & 25 & 50 & 100 & 200 & 300 \\
$m$-cresol & 25 & 50 & 100 & 200 & 400 \\
2-CP & 25 & 50 & 100 & 150 & 200 \\
3-CP & 25 & 50 & 75 & 100 & 125 \\
4-CP & 25 & 50 & 100 & 200 & \\
\hline
\end{tabular}

was equipped with air pump for aeration and a magnetic stirrer for agitation. A feed solution volume of $1400 \mathrm{~mL}$ spiked with increasing concentrations of each of the phenolic compounds as shown in Table 1 was initially prepared in the batch reactor. $600 \mathrm{~mL}$ of activated sludge acclimated to phenol in the SBR $(320 \mathrm{~mL}$ of mixed liquor $+280 \mathrm{~mL}$ of treated effluent from the SBR) was subsequently introduced into the batch reactor with aeration and agitation started instantly. The initial MLVSS concentration in each batch reactor was in the range of approximately $800 \pm 50 \mathrm{mg} / \mathrm{L}$. The $\mathrm{pH}$ and DO concentrations were maintained in the range of $7.5 \pm 0.3$ and $6.0 \pm 0.5 \mathrm{mg} / \mathrm{L}$, respectively, throughout the reaction period. The samples were collected at regular time intervals for the measurement of OUR as well as biomass and phenolic compound concentrations until each of these parameters reached a fairly constant value. The batch experiment was later duplicated for every concentration of each phenolic compound studied (Table 1).

Biomass and phenolic compound concentration analysis

The biomass (in terms of MLVSS) and phenolic compound [determined by 4-aminoantipyrine method (APHA 1998)] concentrations were measured at optical density of 600 and $500 \mathrm{~nm}$, respectively, using spectrophotometer model HALO VIS-10 Visible.

\section{SOUR analysis}

$100 \mathrm{~mL}$ of mixed liquor was initially collected from the batch reactor. The probe of DO meter (model YSI 550A) was inserted into this mixed liquor and agitation started immediately. The DO concentration was recorded every $5 \mathrm{~s}$ until the DO was depleted in the mixed liquor $(<1.0 \mathrm{mg} / \mathrm{L})$. Then, the OUR value was obtained from the slope of the DO concentration against the time plot. The SOUR value was later calculated by dividing the OUR with MLVSS concentration of the mixed liquor at that particular time.

\section{Determination of toxicity percentage}

The toxicity percentage of each phenolic compound acted on the phenol-acclimated activated sludge was calculated using Eq. 1:

$\%$ Toxicity $=\frac{\mu_{\mathrm{b}}-\mu}{\mu_{\mathrm{b}}} \times 100 \%$

where $\mu_{\mathrm{b}}$ and $\mu$ are the specific growth rates for the batch reactors without and with phenolic compounds at different initial concentrations, respectively (Sahinkaya and Dilek 2009).

\section{Results and discussion}

Biodegradation of phenolic compounds

Figure 1 shows the removal efficiencies of each phenolic compound at increasing concentrations in the feed solution by phenol-acclimated activated sludge in the batch reactors. The phenolic compounds of phenol, $o$-cresol, $m$-cresol, and 4-CP were observed to be completely removed by the activated sludge for all the concentrations studied. Another apparent observation was that as the concentration of each of these phenolic compounds increased, longer time was required to achieve complete removal. These results were confirmed by the findings of Saravanan et al. (2008) which also showed that longer time was consumed in degrading higher concentration of phenol by the mixed culture. However, 2-CP and 3-CP were not completely removed even though at the concentration of only $50 \mathrm{mg} / \mathrm{L}$ in the feed solution during the batch studied with phenolacclimated activated sludge. At the concentrations higher that $100 \mathrm{mg} / \mathrm{L}$ of $2-\mathrm{CP}$ and $3-\mathrm{CP}$, only small portion of these phenolic compounds was removed at the beginning of the aeration period. The concentrations of non-removed 2-CP and 3-CP remained relatively constant thereafter throughout the time course. Farrell and Quilty (1999) had documented that the degradation of 2-CP and 3-CP via the meta-cleavage would produce toxic metabolite which inactivated the catechol-2,3-dioxygenase enzyme and prevented further degradation of $2-\mathrm{CP}$ and $3-\mathrm{CP}$. Moreover, 
the accumulation of brown colour polymers as reported in their study was also found in this study with 2-CP and 3-CP in the batch reactors. Thus, it could be concluded that the 2-CP and 3-CP exerted higher toxicity effects than phenol, $o$-cresol, $m$-cresol, and 4-CP which ultimately inhibited their own degradation by phenol acclimated activated sludge.

Effects of phenolic compounds on the growth of phenol-acclimated activated sludge

Figure 2 shows the time courses of biomass concentration in terms of MLVSS at increasing concentrations of phenolic compounds in the feed solution (Table 1). For all the batch experiments studied, it were observed that different concentrations of each phenolic compound showed distinct length of time required to reach the stationary phase of growth. For example, $m$-cresol with the concentrations of 25,50 , and $100 \mathrm{mg} / \mathrm{L}$ reached stationary phase of growth at 6, 20, and $30 \mathrm{~min}$, respectively (Fig. 2c). However, $m$-cresol with the concentrations of 200 and $400 \mathrm{mg} / \mathrm{L}$ required more than 60 and $200 \mathrm{~min}$, respectively, to reach the stationary phase of growth (Fig. 2c). Hence, it could be concluded that the time taken by the activated sludge to reach the stationary phase of growth depended on the concentrations of $m$-cresol in the feed
Fig. 1 Time courses of removal efficiency of various concentrations of phenolic compounds in the batch studies: a phenol, b $o$-cresol, c $m$-cresol, d $2-\mathrm{CP}$, e $3-\mathrm{CP}$, and $\mathbf{f} 4-\mathrm{CP}$
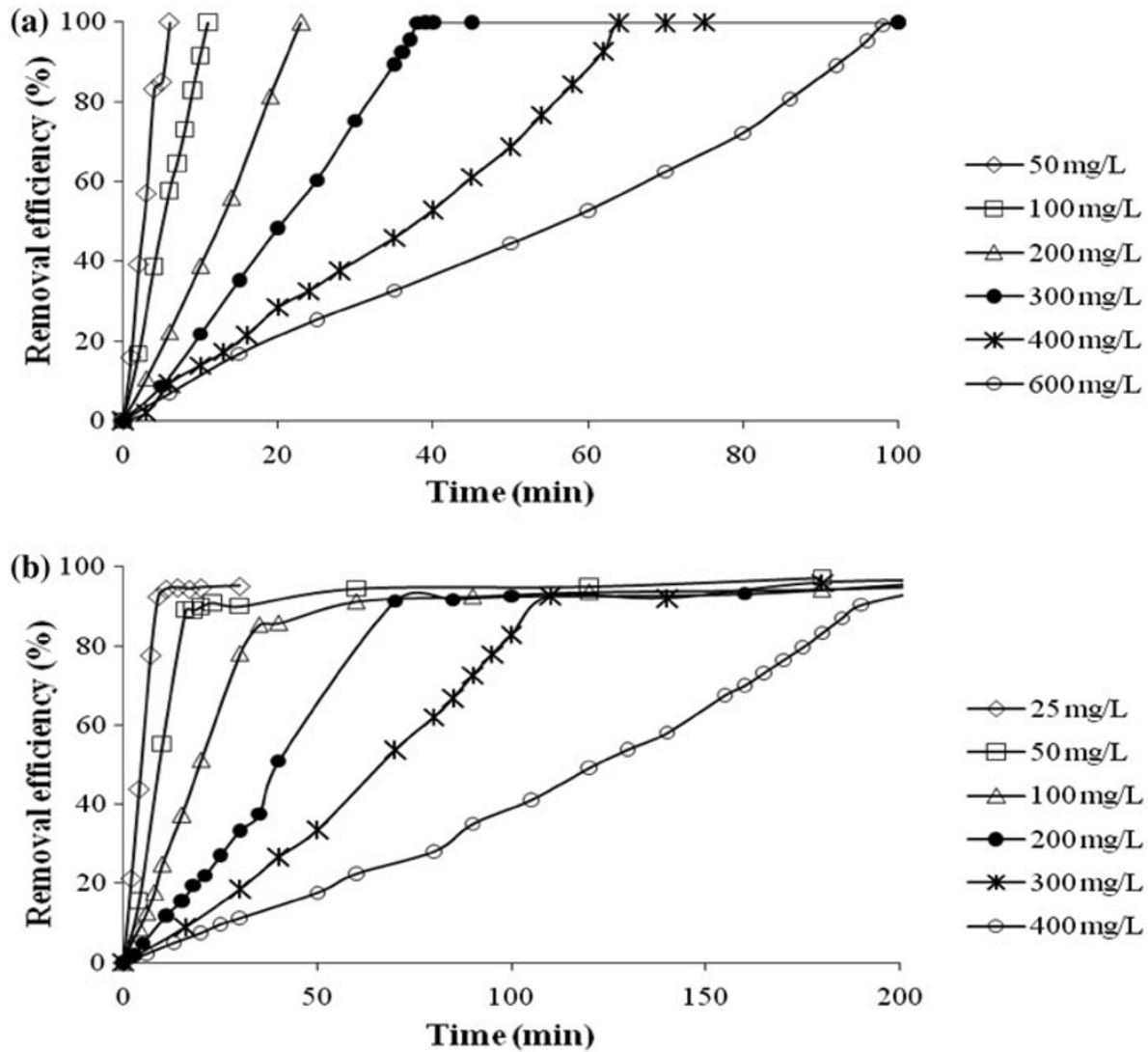

$\smile 25 \mathrm{mg} / \mathrm{L}$

$\square-50 \mathrm{mg} / \mathrm{L}$

$\triangle 100 \mathrm{mg} / \mathrm{L}$

$\rightarrow-200 \mathrm{mg} / \mathrm{L}$

* $-300 \mathrm{mg} / \mathrm{L}$

$-400 \mathrm{mg} / \mathrm{L}$

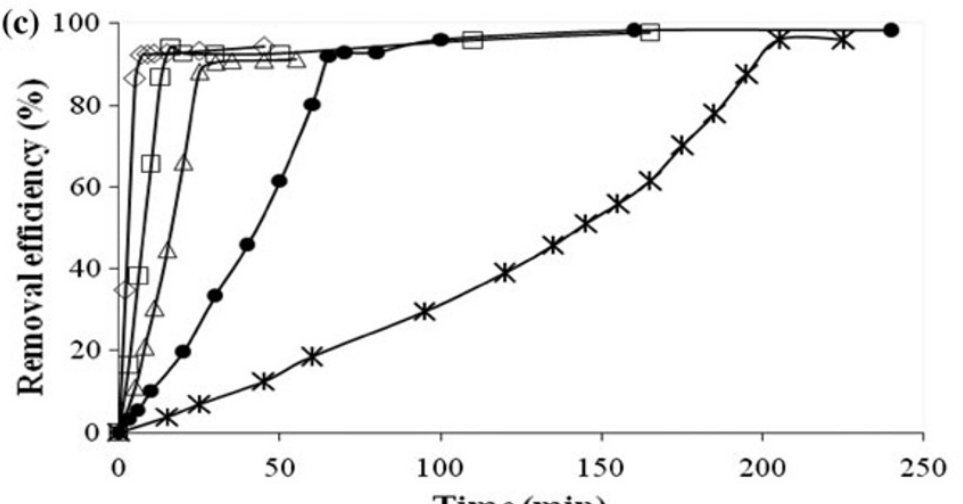

$\leadsto 25 \mathrm{mg} / \mathrm{L}$

$-50 \mathrm{mg} / \mathrm{L}$

$\triangle 100 \mathrm{mg} / \mathrm{L}$

$\longrightarrow-200 \mathrm{mg} / \mathrm{L}$

$\rightarrow-400 \mathrm{mg} / \mathrm{L}$ 
Fig. 1 continued
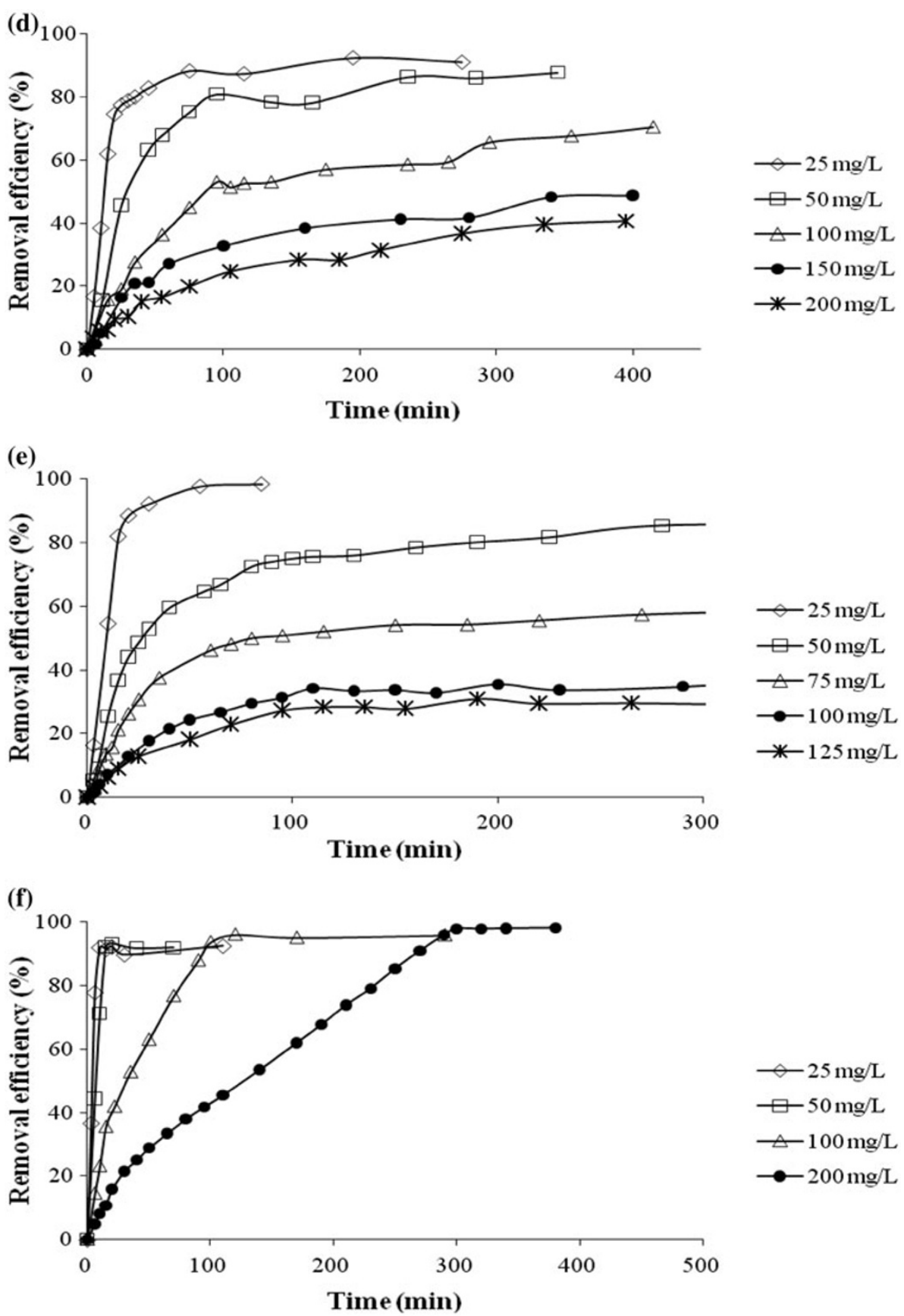

solution. The higher the concentration of $m$-cresol, the longer the time required to reach the stationary phase of growth. Similar observation could be seen for the increasing concentrations of phenol, $o$-cresol, and 4-CP in the feed solution (Fig. 2a, b, f). In addition, the lag phase of growth was also not observed for all the concentrations studied with these phenolic compounds. These results were conflicting with those obtained by Saravanan et al. (2008) which showed lag phase of growth at the phenol concentrations higher than $500 \mathrm{mg} / \mathrm{L}$. A plausible reason to explain the inconsistency was the activated sludge used in these studies had been acclimated to phenol in the SBR for a long period, resulting in its growth in these phenolic compounds at the increasing concentrations without showing the lag phase of growth.

Nonetheless, the growth trends for all the concentrations of 2-CP and 3-CP studied (Fig. 2d, e) were not similar to the phenol, $o$-cresol, $m$-cresol, and 4-CP. When the phenolacclimated activated sludge was in contact with either 2-CP or $3-\mathrm{CP}$, the increasing trend of biomass concentration was very slow which again proved that the toxicity of 2-CP and 3-CP were higher than that of phenol, $o$-cresol, $m$-cresol, and 4-CP. 
Effects of phenolic compounds on the activity of phenol-acclimated activated sludge

The activity of phenol-acclimated activated sludge was measured as SOUR in the presence of various concentrations of phenolic compounds (Fig. 3). The trends of SOUR for a series of different concentrations of o-cresol in the feed solution are represented in Fig. 3b. For every $o$-cresol concentration studied, a specific pattern of SOUR trend could be observed in this figure. In the batch reactors containing 25 , 50 , and $100 \mathrm{mg} / \mathrm{L}$ of $o$-cresol, only one maximum peak of SOUR, i.e., $35.3 \times 10^{-6}, 40.7 \times 10^{-6}$ and $38.3 \times 10^{-6} \mathrm{~g}$ -
$\mathrm{O}_{2} / \mathrm{g}$-MLVSS s, respectively, was detected during the initial period of reaction. These SOUR values decreased rapidly after their respective maximum peak was attained. On the other hand, the batch reactors containing 200,300, and $400 \mathrm{mg} / \mathrm{L}$ of $o$-cresol showed their first peak at the SOUR values of $42.3 \times 10^{-6}, 31.3 \times 10^{-6}$, and $23.7 \times 10^{-6} \mathrm{~g}$ $\mathrm{O}_{2} /$ g-MLVSS s, respectively, during the initial period of reaction. Their second peak of SOUR values arose again at $37.1 \times 10^{-6}, \quad 30.1 \times 10^{-6}$, and $24.8 \times 10^{-6} \mathrm{~g}-\mathrm{O}_{2} / \mathrm{g}-$ MLVSS s, respectively, with the corresponding reaction time of 60, 95, and $160 \mathrm{~min}$. The longer time required for the second peak to appear at higher concentrations of $o$-cresol
Fig. 2 Time courses of biomass concentration in terms of MLVSS in the batch studies with various concentrations of phenolic compounds: a phenol, b $o$-cresol, cm-cresol, d 2-CP, e $3-\mathrm{CP}$, and $\mathbf{f} 4-\mathrm{CP}$
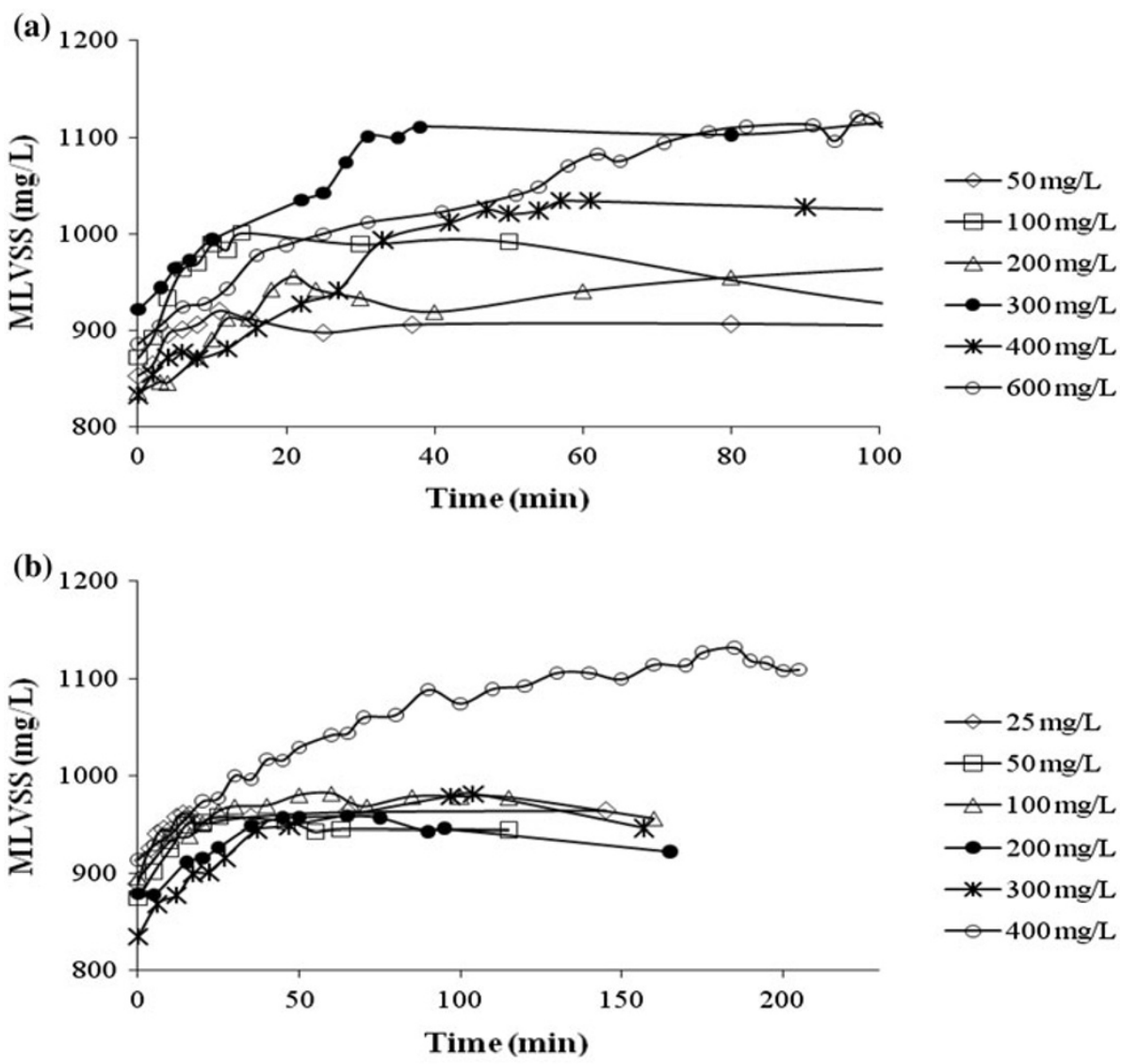

$\smile 25 \mathrm{mg} / \mathrm{L}$
$\square-50 \mathrm{mg} / \mathrm{L}$
$\triangle 100 \mathrm{mg} / \mathrm{L}$
$\multimap-200 \mathrm{mg} / \mathrm{L}$
$\rightarrow-300 \mathrm{mg} / \mathrm{L}$
$\odot-400 \mathrm{mg} / \mathrm{L}$

(c)

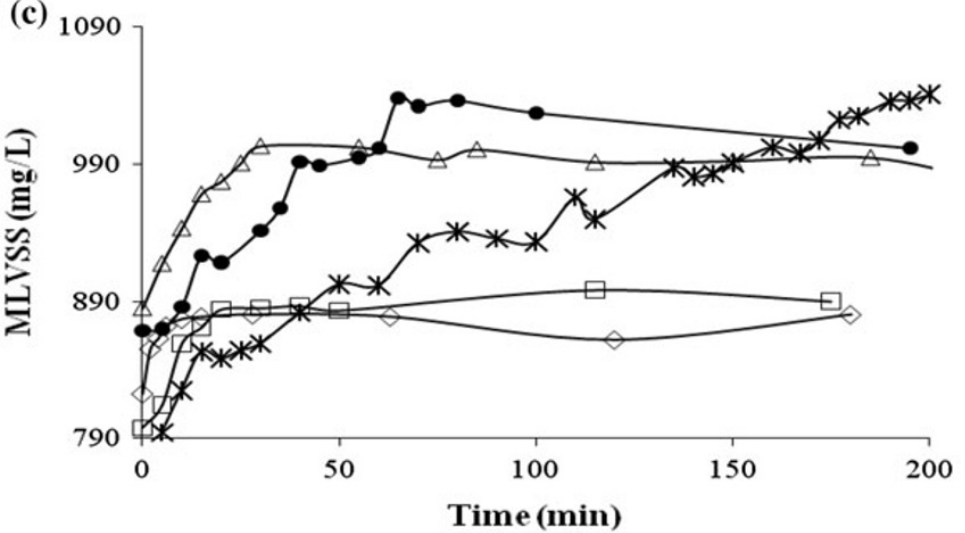


Fig. 2 continued
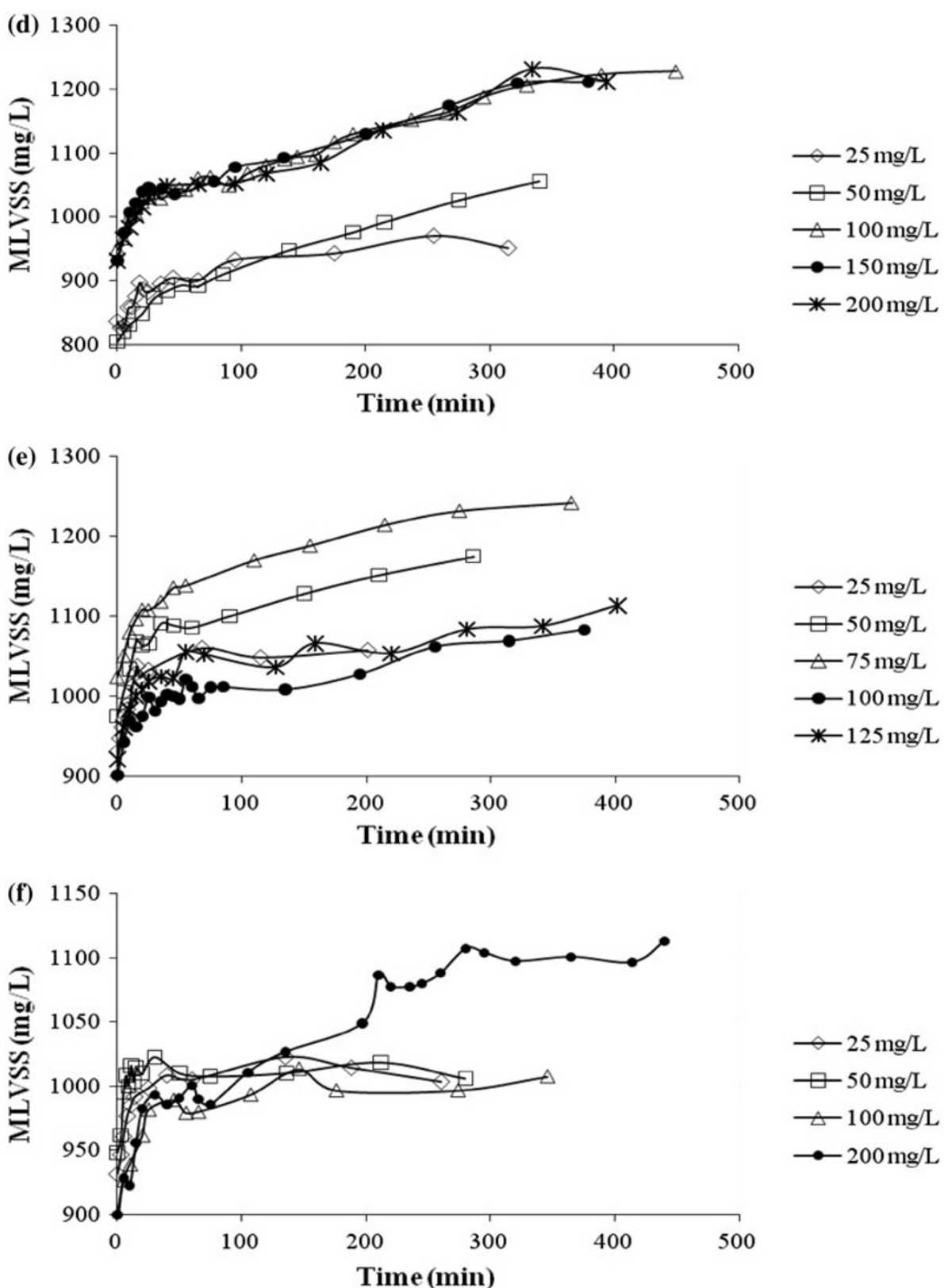

proved that the toxicity effect on the activity of phenolacclimated activated sludge was higher at high concentrations of $o$-cresol. Besides, the higher toxicity effect of $o$-cresol at high concentration was also validated by the maximum peak of SOUR values which generally decreased either at the first or second peak with increasing $o$-cresol concentrations. Similar SOUR patterns were as well observed in the batch experiments containing various concentrations of phenol, $m$-cresol and 4-CP (Fig. 3a, c, f). However, in the batch experiment studies with 2-CP and $3-\mathrm{CP}$, the SOUR values decreased rapidly to below

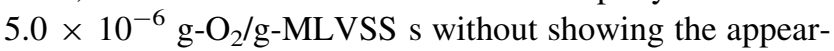
ance of the second peak (Fig. 3d, e). In addition, the maximum SOUR values obtained for $2-\mathrm{CP}$ and $3-\mathrm{CP}$ were generally lower than the peaks of phenol, $o$-cresol, $m$-cresol, and 4-CP at the equivalent concentrations of phenolic compounds in the feed solution. These observations further confirmed that 2-CP and 3-CP exerted higher toxicity effects on the phenol-acclimated activated sludge than phenol, $o$-cresol, $m$-cresol, and 4-CP.

Among the phenol, $o$-cresol, $m$-cresol, and 4-CP, the highest SOUR value was obtained in the batch reactor containing phenol (Fig. 3a) by comparing with the other batch reactors containing phenolic compounds of same concentration. Thus, phenol exerted the lowest toxicity on the activated sludge which was plausibly due to the activated sludge used in the batch experiments had been acclimated to phenol in the SBR system. The phenolic compounds of 
$o$-cresol and $m$-cresol demonstrated about the same SOUR trends for every concentration studied, showing equal toxicity exerted by these cresols on the phenol-acclimated activated sludge. Nevertheless, the SOUR values of these cresols were always higher than that of the 4-CP for all the equivalent concentrations experimented, confirming the 4-CP was more toxic than $o$-cresol and $m$-cresol.

Correlation of phenolic compounds removal, biomass growth and SOUR trends

Overall, the trends of phenolic compounds removal efficiency (Fig. 1) biomass growth (Fig. 2) and SOUR (Fig. 3) were closely related. It was observed that when the percentage removal efficiency of phenolic compounds reached $100 \%$, the value of SOUR dropped rapidly with the growth of biomass achieving stationary phase of growth, and all happened almost simultaneously. For example, during the batch study with phenol concentration of $600 \mathrm{mg} / \mathrm{L}$ in the feed solution, the time required to completely remove phenol in the mixed liquor, the attainment of stationary phase of growth and the SOUR value dropped to the lowest value occurred at 100,97 , and $101 \mathrm{~min}$, respectively (Figs. 1a, 2a and 3a, respectively). Similar observation could be as well detected for all the concentrations studied for $o$-cresol, $m$-cresol, and $4-\mathrm{CP}$. Thus, the
Fig. 3 Time courses of SOUR in the batch studies with various concentrations of phenolic compounds: a phenol, b $o$-cresol, c $m$-cresol, d 2-CP, e $3-\mathrm{CP}$, and $\mathbf{f} 4-\mathrm{CP}$

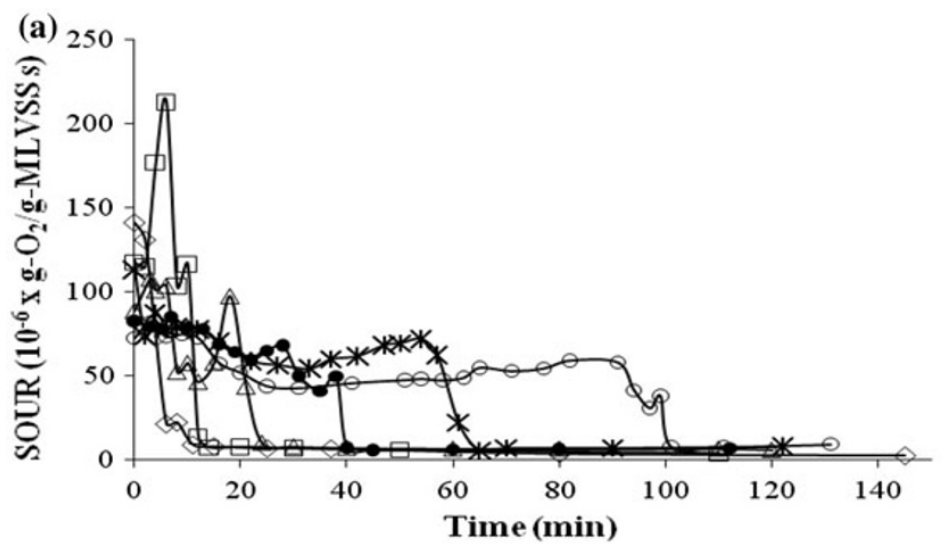

$\smile 50 \mathrm{mg} / \mathrm{L}$

$\square-100 \mathrm{mg} / \mathrm{L}$

$\triangle 200 \mathrm{mg} / \mathrm{L}$

$\longrightarrow 300 \mathrm{mg} / \mathrm{L}$

* $-400 \mathrm{mg} / \mathrm{L}$

- $600 \mathrm{mg} / \mathrm{L}$

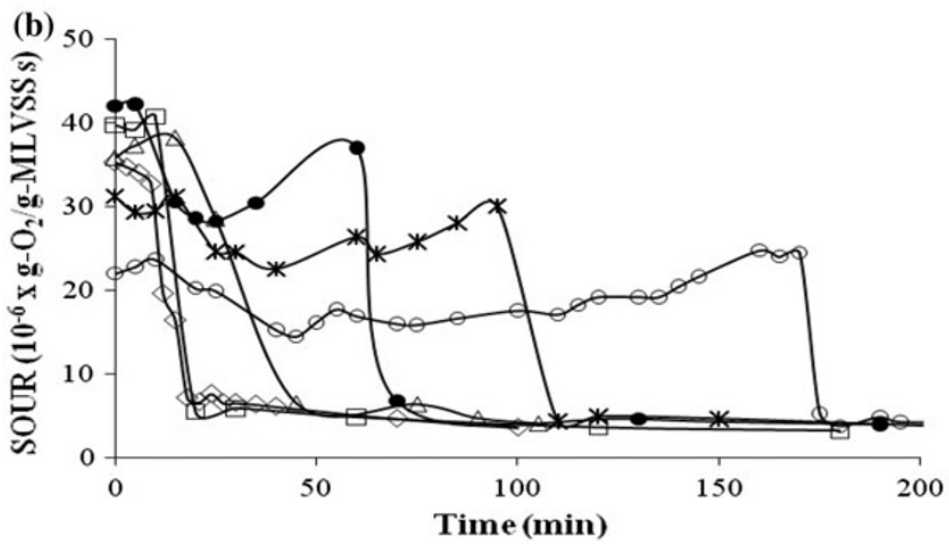

$\smile 25 \mathrm{mg} / \mathrm{L}$
$\square 50 \mathrm{mg} / \mathrm{L}$
$\triangle 100 \mathrm{mg} / \mathrm{L}$
$\multimap 200 \mathrm{mg} / \mathrm{L}$
$*-300 \mathrm{mg} / \mathrm{L}$
$\multimap 400 \mathrm{mg} / \mathrm{L}$

(c)

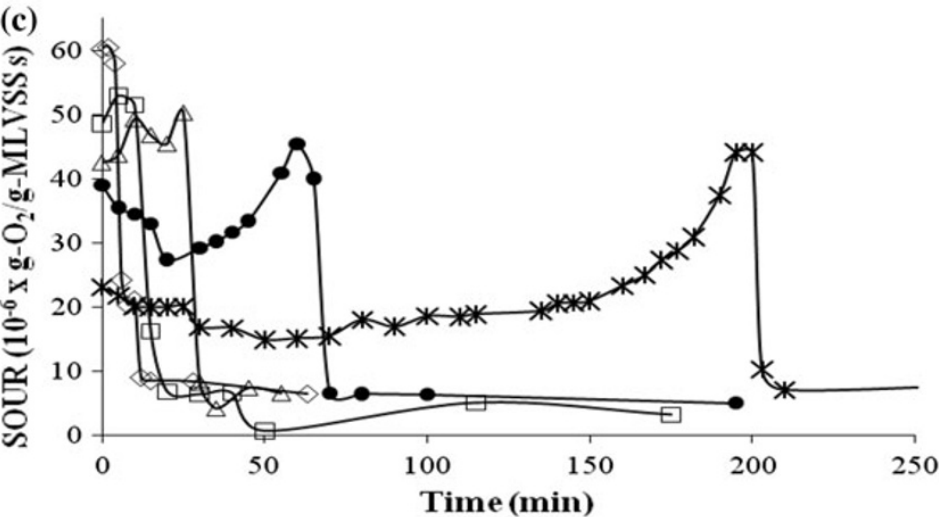

$\frown 25 \mathrm{mg} / \mathrm{L}$

$\square-50 \mathrm{mg} / \mathrm{L}$

$\triangle 100 \mathrm{mg} / \mathrm{L}$

$\rightarrow-200 \mathrm{mg} / \mathrm{L}$

* $-400 \mathrm{mg} / \mathrm{L}$ 
Fig. 3 continued
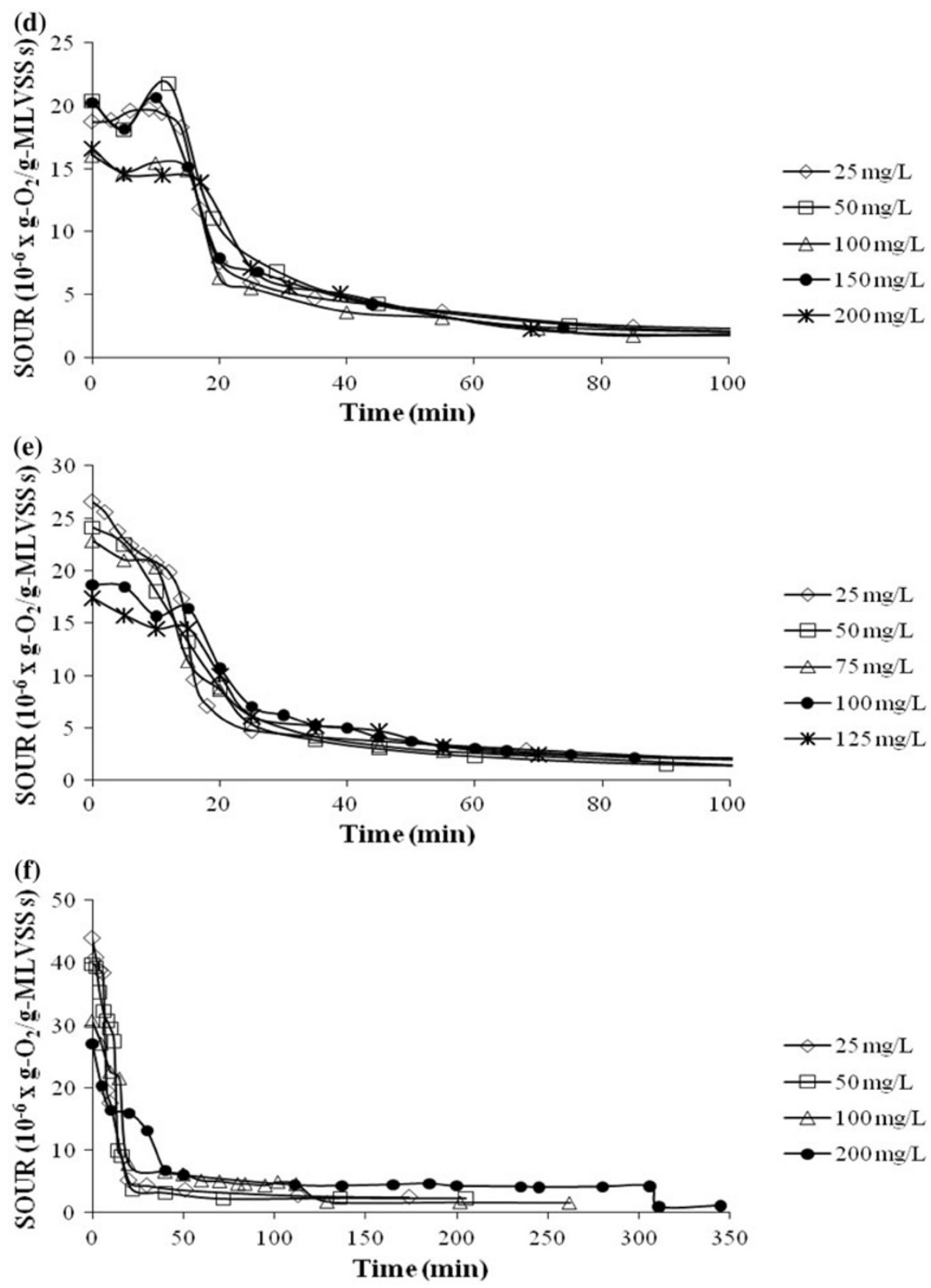

SOUR patterns generated during the batch experiments with the aforementioned phenolic compounds could be used as a reference to detect the end point of phenolic compounds degradation and monitor the biomass growth in the wastewater treatment plants. Yoong et al. (2000) had shown that the phenol COD substrate levels could be tracked from the OUR values and agreed that the OUR was a good indicator of biological activity which offered a fast response method for controlling the performance of the SBR. Furthermore, according to the Meric et al. (2003), the OUR measurement as well had become a useful tool to determine the growth characteristics of biological treatment systems. However, these methods could not be applied for 2-CP and 3-CP due to the inhibition effects exerted on their own degradation.

Toxicity percentages of phenolic compounds exerted on the phenol acclimated activated sludge

Figure 4 shows the toxicity percentages of each phenolic compound studied based on the biomass growth rate as shown in Eq. 1. The negative values of the toxicity percentages represented no inhibition of biomass growth in the batch studies as the specific growth rates of biomass in the presence of phenolic compounds were faster than those without the phenolic compound. Thus, phenol and $m$-cresol 
Fig. 4 Toxicity percentage exerted on the phenolacclimated activated sludge by various concentrations of phenolic compounds in the batch studies

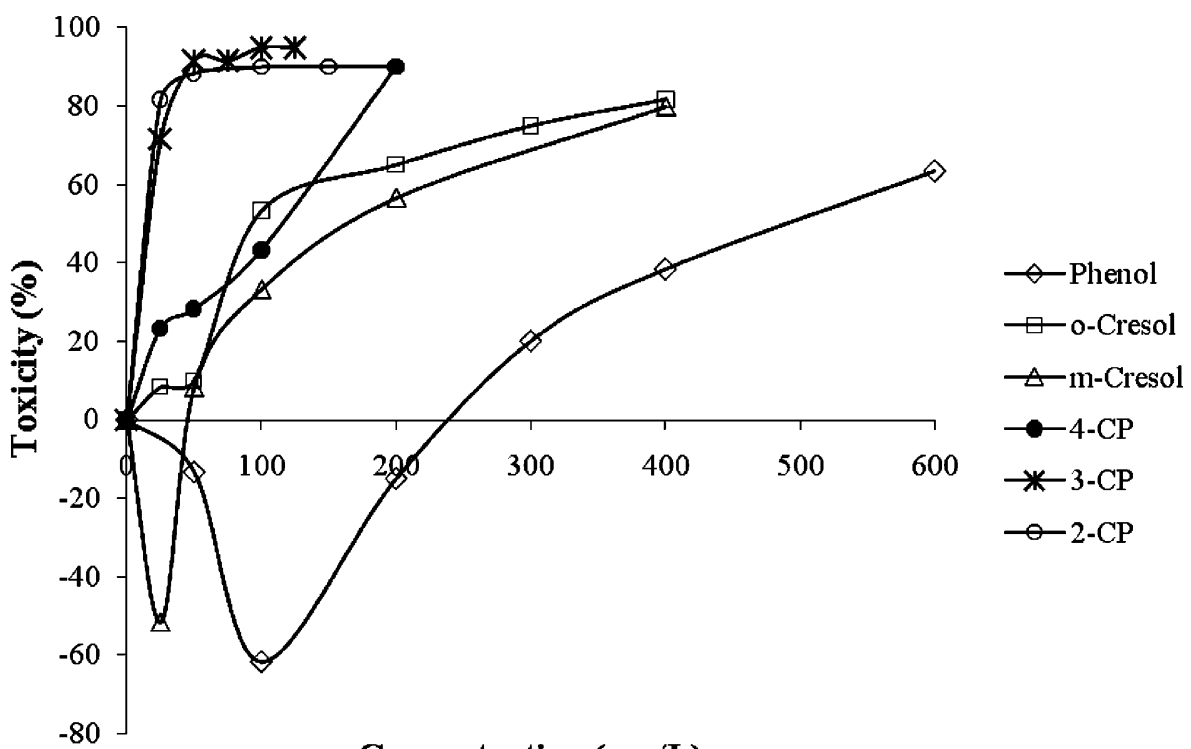

Concentration (mg/L) concentrations below 200 and $25 \mathrm{mg} / \mathrm{L}$ in the feed solution, respectively, did not inhibit the growth of biomass. Dey and Mukherjee (2010) also reported that the growth of cell in the mixed microbial culture was not inhibited at phenol concentration below $300 \mathrm{mg} / \mathrm{L}$. Increasing of phenol concentration in the feed solution to $600 \mathrm{mg} / \mathrm{L}$ would only increase the toxicity percentage to $63 \%$ which was the lowest in comparison with the other phenolic compounds at their highest concentrations studied. This proved the importance of the acclimation process to reduce the toxicity effect when treating high concentrations of the respective organic compound in which the activated sludge had been acclimated early. Furthermore, $O$-cresol and $m$-cresol showed about the same toxicity percentage trends, especially at concentrations higher than $50 \mathrm{mg} / \mathrm{L}$ in the feed solution. These results confirmed that the toxicity effect exerted on the phenol-acclimated activated sludge by $o$-cresol and $m$-cresol was about the same. Among the monochlorophenols, 2-CP and 3-CP showed about the same trends of toxicity percentage and their toxicity percentages were always higher than 4-CP at comparable concentrations studied. These were explicitly shown by the separated batch experiments containing $100 \mathrm{mg} / \mathrm{L}$ of each of these monochlorophenols. The values of toxicity percentage obtained for 2-CP and 3-CP at this concentration were 90 and $95 \%$, respectively, which was insignificantly different from each other. However, the value of toxicity percentage for 4-CP was only $43 \%$ at this concentration and increased further to $90 \%$ at the concentration of $200 \mathrm{mg} / \mathrm{L}$ of $4-\mathrm{CP}$ in the feed solution. Thus, the toxicity effects of phenolic compounds exerted on the phenolacclimated activated sludge followed the order of $2-\mathrm{CP} \approx 3-\mathrm{CP}>4-\mathrm{CP}>o$-cresol $\approx m$-cresol $>$ phenol.

\section{Conclusions}

The phenol-acclimated activated sludge was capable of completely removing phenol, $o$-cresol, $m$-cresol, and 4-CP in the batch experiment studies. However, when the studies were performed using 2-CP and 3-CP, incomplete removal of these phenolic compounds were observed. The biomass growth was also adversely affected in the presence of $2-\mathrm{CP}$ and $3-\mathrm{CP}$ as compared with phenol, $o$-cresol, $m$-cresol, and 4-CP. In addition, the end point of phenol, $o$-cresol, $m$-cresol, and 4-CP degradation and biomass growth could be estimated from their respective SOUR patterns. However, the SOUR patterns of 2-CP and 3-CP were not feasible for this estimation as their presences had retarded their own degradation by the phenol-acclimated activated sludge. Finally, the toxicity percentages values demonstrated that the toxicity effects exerted on the phenol-acclimated activated sludge by phenolic compounds followed the order of 2 -CP $\approx 3$-CP $>4-\mathrm{CP}>o$-cresol $\approx m$-cresol $>$ phenol.

Acknowledgments This work was supported by the Universiti Sains Malaysia under the Research University (RU) Grant No.1001/ PKIMIA/814149. One of the authors, Jun-Wei Lim, wishes to acknowledge the financial support from USM Fellowship Scheme and MyBrain $15(\mathrm{MyPhD})$ programme.

Open Access This article is distributed under the terms of the Creative Commons Attribution License which permits any use, distribution, and reproduction in any medium, provided the original author(s) and the source are credited.

\section{References}

APHA (1998) Standard methods for the examination of water and wastewater, 20th edn. America Public Health Association, Washington, DC 
Archibald F, Methot M, Young F, Paice MG (2001) A simple system to rapidly monitor activated sludge health and performance. Water Res 35(10):2543-2553

Arslan-Alaton I, Akmehmet Balcioglu I (2002) Biodegradability assessment of ozonated raw and biotreated pharmaceutical wastewater. Arch Environ Contam Toxicol 43(4):425-431

Cervantes FJ, Pavlostathis SG, van Haandel AC (2006) Advanced biological treatment processes for industrial wastewaters. IWA Publishing, London

Dey S, Mukherjee S (2010) Performance and kinetic evaluation of phenol biodegradation by mixed microbial culture in a batch reactor. Int J Water Resour Environ Eng 2(3):40-49

Farrell A, Quilty B (1999) Degradation of mono-chlorophenols by a mixed microbial community via a meta-cleavage pathway. Biodegradation 10(5):353-362

Kim GY, Moon SH (2005) Degradation of pentachlorophenol by an electroenzymatic method using immobilized peroxidase enzyme. Korean J Chem Eng 22(1):52-60

Lee HC, In JH, Kim JH, Hwang KY, Lee CH (2005) Kinetic analysis for decomposition of 2,4-dichlorophenol by supercritical water oxidation. Korean J Chem Eng 22(6):882-888

Leong ML, Lee KM, Lai SO, Ooi BS (2011) Sludge characteristics and performances of the sequencing batch reactor at different influent phenol concentrations. Desalination 270(1-3):181-187

Meric S, Eremektar G, Ciner F, Tunay O (2003) An OUR-based approach to determine the toxic effects of 2,4-dichlorophenoxyacetic acid in activated sludge. J Hazard Mater 101(2):147-155

Michalowicz J, Duda W (2007) Phenols-sources and toxicity. Polish J Environ Stud 16(3):347-362
Moharikar A, Purohit HJ (2003) Specific ratio and survival of Pseudomonas CF600 as co-culture for phenol degradation in continuous cultivation. Int Biodeterior Biodegrad 52(4): 255-260

Nuhoglu A, Yalcin B (2005) Modelling of phenol removal in a batch reactor. Process Biochem 40(3-4):1233-1239

Sahinkaya E, Dilek FB (2009) The growth behavior of Chlorella vulgaris in the presence of 4-chlorophenol and 2,4-dichlorophenol. Ecotoxicol Environ Saf 72(3):781-786

Saravanan P, Pakshirajan K, Saha P ((2011)) Studies on growth kinetics of predominantly Pseudomonas sp. in internal loop airlift bioreactor using phenol and $m$-cresol. Korean J Chem Eng 28(7):1550-1555

Saravanan P, Pakshirajan K, Saha P (2008) Growth kinetics of an indigenous mixed microbial consortium during phenol degradation in a batch reactor. Bioresour Technol 99(1):205-209

Yoong ET, Lant PA, Greenfield PF (2000) In situ respirometry in an SBR treating wastewater with high phenol concentrations. Water Res 34(1):239-245

Young JC (1999) Oxygen uptake rate as a monitoring and control parameter for activated sludge processes. In: WEF/Indiana Water Pollution Control Association (IAWPCA) Purdue University Industrial Wastes Technical Conference. Hyatt Regency Indianapolis, IN

Zhao Z, Jiang G, Jiang S, Ding F (2009) Integrated anaerobic/aerobic biodegradation in an internal airlift loop reactor for phenol wastewater treatment. Korean J Chem Eng 26(6):1662-1667 